\title{
Intervenção Psicológica com Pessoas com Deficiência em Situação Asilar ${ }^{1}$
}

\author{
Psychological Intervention With Disabled
} People In An Asylum

Intervención Psicológica Con

Personas Con Deficiencia En Situación De Asilo

Iracema Neno Cecilio Tada, Cíntia Frota Bisconsin, Dyana Cristhina de Freitas, Edlei Timbó Passos, Grazielly Teles Nascimento, Joseline Souza Castro, Josiana Paula Gomes do Nascimento, Junior Cesar Minin \& Lidiane Ferreira Leite

Universidade Federal de Rondônia 
Resumo: Este artigo relata a intervenção psicológica com cinco pessoas com deficiência em situação asilar, realizada por oito graduandos de Psicologia, tendo como referencial teórico a Psicologia histórico-cultural. A intervenção objetivou favorecer o desenvolvimento das funções psicológicas superiores dos asilados por meio da mediação desenvolvida pelos graduandos em passeios quinzenais realizados em locais públicos da cidade de Porto Velho/RO, ricos em estímulos ambientais e em oportunidades interativas diversificadas, no período de março a outubro/2009. Nos passeios, aspectos da atenção, concentração, memória, comunicação gestual, verbal e trocas interativas foram observados e incentivados. A intervenção possibilitou às pessoas com deficiência vivenciarem situações que as desafiassem, rompendo a rotina monótona e pouco estimulante de seu cotidiano de internação a fim de que pudessem apropriar-se de condutas e de normas sociais que colaborassem para o seu processo de humanização. Aos discentes, essa experiência permitiu a atuação junto às pessoas com deficiência bem como maior aprofundamento dos conhecimentos em Psicologia histórico-cultural.

Palavras-chave: Deficiência. Psicologia histórico-cultural. Intervenção psicológica. Inclusão social.

Abstract: This article relates the psychological intervention with five disabled people in an asylum, held by eight psychology undergraduation students, taking as theoretical reference the historical cultural psychology. The intervention aimed to promote the superior psychological functions of the disabled through the mediation of the students in biweekly rides conducted in public halls in the city of Porto Velho/ $\mathrm{RO}$, rich in environmental stimulus and diverse interactive opportunities, from March to October/2009. In the rides, aspects of attention, concentration, memory, gestural communication, verbal and interactive exchanges were observed and encouraged. The intervention made it possible for the disabled people to get into situations that defied them to break the dull routine and that are not very stimulating for their confinement, so that they could develop behavior and social norms that might contribute to their humanization process. This experience allowed the students to work with disabled people as well as further deepen the historical cultural psychology knowledge.

Keywords: Deficiency. Historical cultural psychology. Psychological intervention. Social inclusion.

Resumen: Este artículo relata la intervención psicológica a cinco personas con deficiencia en situación de asilo, realizado por ocho graduandos de Psicología, teniendo como referencial teórico la Psicología Histórico Cultural. La intervención objetivó favorecer el desarrollo de las funciones psicológicas superiores de los asilados por medio de la mediación con los graduandos en paseos quincenales realizados en lugares públicos de la ciudad de Porto Velho/RO, ricos en estímulos ambientales y en oportunidades interactivas diversificadas, en el período de marzo a octubre/2009. En los paseos, aspectos de la atención, concentración, memoria, comunicación gestual, verbal e intercambios interactivos fueron observados e incentivados. La intervención posibilitó a las personas con deficiencia vivir situaciones que la desafiasen rompiendo con la rutina monótona y poco estimulante de su cotidiano de internación, apropiándose de conductas y normas sociales colaborando para su proceso de humanización. A los discentes, esta experiencia les permitió la actuación junto a las personas con deficiencia así como mayor profundización sobre la Psicología Histórico Cultural.

Palabras clave: Deficiencia. Psicología Histórico Cultural. Intervención psicológica. Inclusión social.

Para nós, que atuamos na área da deficiência, foi uma surpresa encontrar uma instituição asilar em pleno século XXI em nosso Estado, considerando a discussão acadêmica e social em relação à inclusão social. Lá encontramos 8 pessoas, com idades entre 7 a 31 anos, 5 rapazes e 3 moças, a maioria com grave quadro de deficiência múltipla e 1 com autismo. Para Bueno, as práticas de internação de pessoas com deficiência grave permitem a criação de uma identidade social pautada na necessidade de segregá-las do convívio com os indivíduos normais, sem deficiência, o que contribui para a criação de uma "auto-imagem de incapacidade e de inferioridade" das que têm anomalias (1997, p.175).

A instituição asilar criada por uma organização não governamental (ONG) vem atendendo a população com deficiência múltipla ambulatorialmente, desde a década de 90, com serviços de fonoaudiologia, fisioterapia, neurologia, nutrição, estimulação e cuidados básicos de higiene e saúde, e cuida de cerca de 120 pessoas com deficiência por mês.

A rotina das oito pessoas institucionalizadas 
Zanella explica

que, na

perspectiva

vigotskiana, as

relações sociais

"extrapolam

os limites das

ações em si e as

conectam com

muitas outras,

possibilitando a

compreensão

dos diversos

elementos

envolvidos, de

outros possiveis

e de como estes

se relacionam"

caracterizando-

se assim, como

atividade

humana, por

meio do processo

de objetivação

e subjetivação

"mediada por

signos" (2004,

p. 132). consiste, no período da manhã, em participar das atividades desenvolvidas com os pacientes ambulatoriais nas salas de estimulação. À tarde, permanecem na casa asilar - que fica no mesmo terreno do prédio ambulatorial assistindo televisão, recebendo cuidados de higiene e medicação. Realizam suas refeições na instituição com a ajuda de monitoras. Durante os finais de semana, três internos vão para suas casas a fim de conviver com os familiares, e cinco permanecem na casa asilar com poucas atividades desenvolvidas por contarem com apenas uma monitora e visitas esporádicas de voluntárias. Isso quer dizer que as pessoas em situação asilar passam a maior parte da vida dentro da instituição, saindo apenas para consulta médica, e têm poucas oportunidades de convivência com pessoas que não pertencem à instituição, poucas ocasiões de convivência em lugares distintos da ONG ou de consultórios médicos, com menos chances interativas diversificadas no seu cotidiano.

Além dessa situação, observamos em nosso trabalho com a instituição a prática infantilizada dos profissionais em lidar com os pacientes ambulatoriais e asilares, chamandoos às vezes de bebês ${ }^{2}$ independentemente da idade. Essa mesma situação foi verificada por De Carlo em uma instituição asilar que atendia internos com deficiência na faixa etária de 18 a 45 anos, e que, por serem tratados como crianças, se assumiram "como crianças, que é uma forma de reprodução (eco), na sua própria fala, do discurso social que infantiliza" (2001, p. 52).

Ser infantilizado é desconsiderar a condição de adolescente ou de adulto da pessoa com deficiência, é desacreditar em seu desenvolvimento, é aprisioná-la na qualidade de dependente, é torná-la alienada.

As relações sociais, para Vigotski, são a base da construção das funções psicológicas superiores do indivíduo, como, por exemplo, a atenção, a memória, a abstração e o raciocínio lógico, dentre outras - porque, para o autor (1995), toda função psíquica superior, em princípio, é social - interpsíquica - por surgir primeiro no plano social para depois surgir no plano psicológico - intrapsíquica -, passando depois a ser interna. Assim, normas de comportamentos, de ética e de conhecimento cultural vão sendo apreendidos e internalizados pelo indivíduo em desenvolvimento por meio da vida social.

Esse processo de apreensão e de internalização ocorre por meio da mediação semiótica, que confere a dimensão humana à atividade instrumental "pelos instrumentos técnicos orientados para regular as ações sobre os objetos, e pelos sistemas de signos, orientados para regular as ações sobre o psiquismo dos outros e de si mesmo" (Sirgado, 1990, p. 66, grifos do autor).

Zanella explica que, na perspectiva vigotskiana, as relações sociais "extrapolam os limites das ações em si e as conectam com muitas outras, possibilitando a compreensão dos diversos elementos envolvidos, de outros possíveis e de como estes se relacionam" caracterizando-se assim, como atividade humana, por meio do processo de objetivação e subjetivação "mediada por signos" (2004, p.132).

Esse processo de humanização "só é possível na relação com outros homens", e não pode, portanto, compreender as pessoas como "seres em si, já que, para viver, necessitam estabelecer relações de interdependência", como analisa Meira (2007, p. 45). A existência dos homens "é redigida por leis históricas, e não por mecanismos naturais ou biológicos" (Pino, 2000, pp. 59-60, grifos do autor).

O processo de institucionalização trará, na análise de Tada (2009), consequências negativas para o desenvolvimento do indivíduo, uma vez que as relações 
interpessoais estabelecidas no interior da instituição tendem a ocorrer estritamente entre a pessoa institucionalizada e seus pares com deficiência, em uma rotina geralmente pouco desafiadora.

A falta de oportunidades interativas com pessoas sem deficiência favorecerá, segundo Vigotski (1997), o desenvolvimento de hábitos e condutas que distanciam a pessoa com deficiência do contexto cultural, aumentando o seu desajustamento social.

Podemos afirmar que o processo de institucionalização ocorre porque a nossa sociedade não se encontra preparada para receber a pessoa deficiente, e constrói, como analisa Vigotski (1997, p.17), "instrumentos materiais e adaptações, (...) aparatos e instituições psicológicas (...) destinadas à organização psicofisiológica normal".

Dessa forma, para o autor, com quem concordamos, o estado patogênico e anormal só é sentido pela pessoa deficiente como resultado de sua experiência social, tendo a deficiência alterado as suas formas sociais de conduta, contribuindo para um sentimento de desvalorização social que lhe é atribuído pela pessoa sem deficiência em função da anomalia, sendo essa uma das principais dificuldades para a promoção de sua aprendizagem e desenvolvimento.

Diante da institucionalização de oito pessoas com deficiência e por acreditarmos na importância de sua inserção social em nossa cidade e no papel determinante exercido pelas relações sociais no desenvolvimento das funções psicológicas superiores é que desenvolvemos esta intervenção psicológica, buscando dar oportunidade aos internos

3 MSD: membro superior direito; MID: membro inferior direito; MS: membro superior; MI: membro inferior. de vivenciarem situações do cotidiano em ambientes públicos, ricos em estímulos e em possibilidades interativas diversificadas por nós mediadas.

\section{Metodologia}

Aqui apresentamos algumas informações obtidas por meio do prontuário sobre as cinco pessoas em situação asilar que participaram da intervenção psicológica, todas com nomes fictícios:

Gracinha: 31 anos; em situação asilar há cinco anos. Abandonada pela família quando tinha oito anos de idade, foi encaminhada para a Casa do Adolescente e depois para a ONG; diagnóstico: encefalopatia crônica, com déficit intelectual grave, epilepsia, psiquismo normal e deficiência visual grave. Locomove-se com autonomia. Apresenta comunicação verbal.

César: 25 anos; em situação asilar há quatro anos; pais falecidos; filho único; diagnóstico: suspeita de hidrocefalia e de deficiência intelectual, hemiparesia direita, com hipotrofia MSD/MID ${ }^{3}$, MMS em posição característica do hemiplégico, marcha hemiplégico, encurtamento dos flexores do MS, ADM pouco limitada para ombro e cotovelo; apresenta encurtamento considerável do $\mathrm{MI}$, anda com dificuldade, precisando, constantemente, de cadeira de rodas. Tem crises convulsivas. Fala estereotipada e limitada a três palavras: "tio, legal" e a seu próprio nome.

Rubens: 13 anos; em situação asilar há sete anos; pais separados; tem dois irmãos mais novos; diagnóstico: paralisia cerebral, epilepsia e disfagia. Não firma o pescoço, e faz uso de cadeira de rodas. Não apresenta comunicação verbal e permanece a maior parte do tempo dormindo ou com o olhar fixo no vazio.

Alicia: 13 anos; em situação asilar há um ano; os pais vivem com os outros três filhos; diagnóstico: paralisia cerebral e crises convulsivas. Não anda, faz uso de cadeira de rodas. Não apresenta comunicação verbal, e 
comunica-se pelo olhar, pelos gestos e pelos movimentos do corpo. Permanece a maior parte do tempo dormindo.

Davi: 11 anos; em situação asilar há seis anos; pais separados; sem referências a irmãos; diagnóstico: autismo, hipotrofia generalizada, retardo mental neuropsicomotor. Tem autonomia no andar. Expressa-se por meio de comunicação não verbal.

Analisando as características de cada pessoa envolvida neste projeto de extensão, definimos as parcerias fixas - aluno de Psicologia ${ }^{4}$ e pessoa deficiente em situação asilar.

A discente Grazielly, por ser bem comunicativa e por identificar-se com Gracinha, foi a sua parceira. Para César, consideramos importante a companhia de Junior, para que pudesse estabelecer interação com uma pessoa do gênero masculino por conviver em um ambiente constituído principalmente por mulheres. Rubens ficou com Dyana e Cíntia, em decorrência da gravidade do seu quadro clínico, o mesmo acontecendo com Alicia, que contou com a dupla Josiana e Joseline. Já para Davi, por ter o hábito de iniciar a marcha repentinamente, sem rumo, colocando sua vida em risco e rebelandose quando é interrompido nessa ação, escolhemos Lidiane e Edlei.

Iniciamos a atividade na própria casa asilar, para que as pessoas com deficiência e os discentes pudessem se conhecer. Os passeios que aconteceram nos finais de semana foram planejados para serem quinzenais, objetivando trabalhar com a familiarização do ambiente e analisar aspectos relacionados à atenção e à memória, mas nem sempre foi possível manter esse intervalo em decorrência de problemas com o veículo da instituição que nos levava para os lugares públicos ou em decorrência das atividades sociais alterados.
No período de março a outubro/2009, realizamos dez passeios nos seguintes locais: uma faculdade privada, três parques públicos, aeroporto, um shopping e uma casa de cultura. Nos parques e na casa de cultura, foi feita uma só visita pelos motivos elencados anteriormente.

Como método de avaliação do desenvolvimento das funções psicológicas superiores das pessoas com deficiência, pautamos nossa análise em uma perspectiva qualitativa (Braga, 1995), que privilegia a observação dos fatos em detrimento da mensuração quantitativa realizada por testes psicológicos.

Assim, ao término de cada passeio, os discentes relatavam os fatos observados em seu diário de campo, para que pudéssemos analisar o ocorrido nas supervisões que ocorreram quinzenalmente e que foram intercaladas com grupos de estudo, aproximando teoria e prática.

\section{Resultados e discussão}

Neste tópico, apresentaremos uma síntese do trabalho desenvolvido com cada pessoa em situação asilar.

Gracinha: nos primeiros passeios, mostrouse dependente em atividades como ir ao banheiro, calçar-se e vestir-se, solicitando nossa ajuda. Dessa forma, a mediação com Gracinha ocorreu principalmente por meio da orientação verbal para que executasse as ações de maneira autônoma, mostrando que era capaz de fazer isso sozinha, tendo ela tido êxito nessas atividades. Gracinha internalizou a ação cultural de cuidados e de higiene pessoal a partir do momento em que foi tratada como pessoa, independentemente de sua deficiência. Isso indica que, na instituição asilar, as relações sociais são pautadas na deficiência, o que, para Vigotski (1997), contribui para o desenvolvimento 
de hábitos e de condutas inadequadas que fazem aumentar o desajustamento social dos internos.

Outro exemplo desse desajustamento foi a oscilação de Gracinha entre condutas infantis (birras) e adultas (iniciativa de diálogo e contra-argumentação, habilidades de negociação e boa capacidade interpretativa). Como postula Vigotski (1995), é por meio das relações sociais que a pessoa se apropria das normas de conduta, assim, podemos compreender as birras não em função da deficiência de Gracinha, e sim, como fruto das relações institucionais que tendem a considerá-la criança. Essa mesma situação foi verificada por De Carlo (2001) em uma instituição asilar onde os internos com deficiência com idade superior a 18 anos eram tratados como crianças.

César: no tocante à linguagem oral, expressava-se fundamentalmente com palavras repetitivas ou enunciadas em som disforme, de difícil compreensão. Devido a essa dificuldade verbal, buscamos desafiá-lo a expressar-se de forma mais compreensível e coerente, solicitando-se a ele que repetisse suas verbalizações. Decorrente dessa mediação, sua fala tornou-se mais compreensível, o que permitiu melhor comunicação, sendo possível identificar as palavras: obrigado, após ajudá-lo a transpor uma construção de concreto que dificultava a passagem da cadeira de rodas, gostoso, que denotava seu apreço pelo local que visitávamos, e cidade, quando informado sobre o nome do local visitado: Parque Cidade.

Trabalhamos, assim, três processos cognitivos em César: apreensão/processo de significação, em que alguns signos apresentados foram internalizados a partir da mediação semiótica, conceito fundamental na teoria de Vigotski; memória, pela qual César foi incitado a rememorar os signos dos ambientes visitados, e linguagem, considerada por Vygotsky representação por excelência do desenvolvimento cognitivo. Observamos em César uma elaboração verbal cada vez mais complexa e lexicamente mais ampla. De acordo com Vygotsky, a internalização "dos sistemas de signos produzidos culturalmente provoca transformações comportamentais e estabelece um elo de ligação entre as formas iniciais e tardias do desenvolvimento individual" (1991, p.8).

Outro ponto trabalhado foi que buscasse, em suas relações, chamar as pessoas pelo nome, e não por tio ou tia, destacando-se que essa era a maneira como as pessoas adultas como ele se tratavam, mas não tivemos sucesso nessa nossa intervenção, chamando-nos César de tios. Sentimos também dificuldade em fazer com que a ONG se relacionasse com ele de forma adulta. Para Tada, é necessário que as pessoas sem deficiência tenham uma compreensão sobre o "significado do lugar na sociedade do indivíduo que tem uma deficiência, de suas possibilidades" a fim de que "a sociedade possa ter argumentos para se contrapor aos limites construídos historicamente" (2005, p. 205) de exclusão social em função da deficiência, daquilo que o torna diferente.

Rubens: a disfagia atrapalha-o em sua alimentação e respiração, e, no primeiro passeio, necessitou de nossa ajuda para expelir o catarro com frequência, mas, no decorrer dos passeios essa secreção diminuiu. Isso pode ter ocorrido porque, durante os passeios, ficava pouco tempo de cabeça baixa, o que indica o quanto sua estada em ambientes diferentes, ricos em estímulos por nós mediados, ajudou na aquisição de novas posturas. Antes, no começo do desenvolvimento do projeto de extensão, permanecia de cabeça baixa, apático e sonolento.

Outra alteração verificada foi que passou 
a dormir menos durante os passeios, a sorrir e a interagir mais, emitindo alguns sons, permitindo-nos identificar quando estava interessado ou não com o estímulo apresentado. A estreita relação que estabelecemos com ele possibilitou-nos compreendê-lo melhor, e, assim, através de sutis indícios não verbais, respondia aos nossos pedidos e também identificávamos suas vontades. Buscamos valorizar aspectos presentes em suas ações, em seus gestos, em suas pistas não verbais de comunicação, o que, segundo Padilha (2001), constitui uma ação simbólica, ou seja, uma atividade humana.

Alicia: era uma prática dos profissionais da instituição amarrar os braços de Alicia com ataduras na cadeira de rodas para que ela não colocasse as mãos na boca. Isso impedia sua comunicação por meio de gestos e a manipulação de objetos, tão importantes para o seu desenvolvimento. Com o decorrer dos passeios, conseguimos convencê-los a retirar as ataduras; Alicia livre, inicialmente, tentou colocar as mãos na boca, mas, ao ouvir nossa orientação de que não devia fazer isso, parava e sorria, não as colocando mais na boca durante a execução de nosso projeto.

Tirar a mão da boca quando solicitado indicou que Alicia compreendia as solicitações verbais, o que demonstra o desenvolvimento das seguintes funções psicológicas superiores: atenção e raciocínio lógico. Ao mesmo tempo, contribuiu para que ela indicasse, por meio de gestos, o que queria, tentando às vezes comunicar-se por meio de sons. É a partir de relações constituídas de formas diversificadas que se pode, de acordo com Padilha, apreender "os indícios, sinais" que a pessoa com deficiência que não dispõe da comunicação verbal "nos dá sobre seu processo evolutivo e pelo qual ela se aproxima da resolução de suas dificuldades" (2001, p.177).

O fato de não estar mais amarrada abriu-lhe um leque de comunicação - gestual e verbal - que antes pouco aparecia por passar mais tempo dormindo amarrada em sua cadeira.

Davi: é um jovem cheio de energia, interage esporadicamente com pessoas e, quando o faz, demonstra satisfação. Em alguns momentos em nossos passeios, buscou abraçar os transeuntes, demonstrando afetividade. Comumente, não costumava responder aos nossos pedidos, alternando momentos de interação e de desinteresse para conosco e para algumas atividades. Uma das principais comunicações corporais de Davi refere-se a sentar-se no chão, por vezes indicando que está descontente com alguma situação, fato ou vivência que lhe é apresentada.

Apresentou, em alguns momentos, inexpressividade corporal, com o olhar fixo em algo que não conseguimos identificar, como se não estivesse ali presente, característica comum às pessoas com autismo, segundo Salvador (1993). Quando isso ocorria, buscávamos chamar a sua atenção para algum objeto ou situação do cotidiano, e demorava um pouco para nos atender.

Davi demonstrou-se mais confiante em locais abertos com poucas pessoas, e mostrava-se irrequieto e irritadiço em locais fechados e barulhentos, como o shopping.

Inicialmente, quando chegava aos ambientes visitados, observava ao seu redor e depois caminhava, muitas vezes sem perceber aonde ia, e depois, permanecia atento a algo. Era nesse momento, quando estímulos significativos atraíam a sua atenção, que buscávamos relacionar-nos com ele, contextualizando em relação ao seu foco de atenção, transformando esses estímulos em representações para Davi, que conferem a ele um mundo simbólico, que the dão a dimensão humana, como discutido por Meira (2007) e Zanella (2004), pelo processo de objetivação e subjetivação na relação com os outros por meio da mediação 
semiótica.

Estar em locais sociais distintos da casa asilar permitiu a ele novas oportunidades interativas, como verificado por nós no Parque Cidade, ao relacionar-se com uma criança de colo e sua família, pessoas que foram atenciosas com Davi, que sorriu diversas vezes para todos e mostrou estar atento à sua conversa.

\section{Considerações finais}

Buscamos, com o desenvolvimento deste projeto de extensão, favorecer a inclusão social e o desenvolvimento das funções psicológicas superiores para as pessoas com deficiência em situação asilar. O contato com ambientes distintos da casa asilar, bem como as interações sociais nelas estabelecidas, contribuíram para o processo de humanização dessas pessoas com deficiência por meio do processo de mediação semiótica desenvolvida na relação conosco estabelecida. Apresentamos novas possibilidades de se constituírem como sujeitos a partir da internalização de signos até então desconhecidos, como discutido por Vigotsky (1991).

Encontramos lugares públicos não acessíveis àqueles que apresentam alguma dificuldade de locomoção ou que fazem uso de cadeira de rodas, o que dificultou nossa circulação no local e o desenvolvimento de estratégias de enfrentamento dos obstáculos. Tal situação, analisada por Vigotski (1997) no começo do século XX, deve-se ao fato de a sociedade estar organizada para atender as necessidades das pessoas sem deficiência, e, embora tenha se passado um século, ainda encontramos locais com dificuldade de acesso para as pessoas com deficiência. Observamos também o desconforto de algumas pessoas com a nossa presença, outras que se dirigiam a nós com olhar pesaroso, querendo saber qual era a doença dos asilados, e aquelas que buscaram interagir diretamente com eles independentemente da deficiência.

O projeto também representou um movimento contrário ao padrão habitual de funcionamento da instituição, onde os asilados eram rotineiramente submetidos às mesmas atividades, como, por exemplo, assistir televisão. As monitoras relataram que, com a realização desse projeto, eles se mostravam, na instituição, mais atentos, calmos, alegres, alimentavam-se e dormiam melhor.

Possibilitamos a essas pessoas em situação asilar que vivessem o desafio de sair dos ditames da instituição que cuida deles e que os protege, e se lançassem no novo, no que inda não foi visto e feito, superando aos poucos as incertezas, as resistências e os receios de participar de um meio social que não os acolhe de imediato, mas que sem o qual o seu desenvolvimento se torna limitado, tolhido no sentido da humanização.

Dessa forma, demos o primeiro passo ao desenvolver nossas ações com as pessoas com deficiência em situação asilar, demonstrando que há possibilidade de participarem da vida em sociedade. Mas, para que o seu desenvolvimento continue, sem retrocessos, é fundamental que a instituição asilar invista em parcerias com outras instituições ou que articule, com grupos de voluntariado, atividades fora da instituição, de modo a continuar a realizar passeios em lugares públicos onde possam diversificar suas relações sociais.

Segundo a abordagem teórica vigotskiniana, o Homem se humaniza nas relações sociais, e é a partir dessas relações que ele se apropria "da experiência acumulada pelo gênero humano no decurso da história social" (Meira, 2007, p. 45) por meio da mediação semiótica, o que contribui para o desenvolvimento de suas funções psicológicas superiores. No caso das pessoas com deficiência, 
destacamos a importância dessas relações sociais, que os auxiliam no caminho do processo de compensação da deficiência, que, para Vigotski (1997), ocorre em nível sociopsicológico, ao serem desafiados em situações de experiências significativas em contextos sociais diversificados.

A Psicologia tem contribuído para efetivar mudanças de concepção de Homem e para ampliar nossa visão sobre a pessoa deficiente, com implicações críticas que nos colocam dentro dos assuntos sociais, favorecendo o conhecimento e identificando potenciais de transformação. Quando inserido em projetos de extensão, o futuro psicólogo encontra a possibilidade de expandir seu horizonte de atuação, ao lidar com experiências concretas.

\section{Iracema Neno Cecilio Tada}

Professora-adjunta do curso de Psicologia e do Programa de Pós-Graduação em Psicologia da Universidade Federal de Rondônia. Pesquisadora do Centro de Pesquisa em Formação da Pessoa da Universidade Federal de Rondônia. Doutorado em Psicologia Escolar e do Desenvolvimento Humano pela Universidade de São Paulo, São Paulo - SP - Brasil.

E-mail: iracematada@ig.com.br

\section{Cíntia Frota Bisconsin}

Graduada no Curso de Psicologia na Universidade Federal de Rondônia, Rondônia - RO - Brasil.

E-mail: cintiabisconsin@gmail.com

\section{Dyana Cristhina de Freitas}

Graduada em Psicologia pela Universidade Federal de Rondônia, Rondônia - RO - Brasil.

E-mail: srtady@gmail.com

\section{Edlei Timbó Passos}

Graduado em Psicologia pela Universidade Federal de Rondônia. Psicólogo - Secretaria Estadual de Saúde de Rondônia, Rondônia - RO - Brasil.

E-mail: psic_edlei@hotmail.com

\section{Grazielly Teles Nascimento}

Graduada em Psicologia pela Universidade Federal de Rondônia, Rondônia - RO - Brasil.

E-mail: graziellyteles@yahoo.com.br

\section{Joseline Souza Castro}

Graduada em Psicologia pela Universidade Federal de Rondônia, Rondônia - RO - Brasil.

E-mail: joseline.castro@hotmail.com

\section{Josiana Paula Gomes do Nascimento}

Graduada em Pedagogia pela Universidade Federal de Rondônia, campus de Rolim de Moura - RO - Brasil. Especialização Latu Sensu em Gestão Escolar com Ênfase em Psicologia Educacional pela Faculdade de Rolim de Moura - Rolim de Moura - RO - Brasil.

Graduada em Psicologia pela Universidade Federal de Rondônia - RO - Brasil.

E-mail: josiana_paula@hotmail.com

\section{Junior Cesar Minin}

Graduado em Psicologia pela Universidade Federal de Rondônia, Rondônia - RO - Brasil.

E-mail: jcmminin@hotmail.com

\section{Lidiane Ferreira Leite}

Graduada em Psicologia pela Universidade Federal de Rondônia, Rondônia - RO - Brasil.

E-mail: lidiane.foffy@gmail.com

Endereço para envio de correspondência:

CEPEFOP. Departamento de Psicologia. Universidade Federal de Rondônia. Br 364, km 9,5. Zona Rural. Porto Velho - Rondônia - Brasil - 76808-697 
Braga, L. W. (1995). Cognição e paralisia cerebral: Piaget e Vigotsky em questão. Brasília, DF: Sarah Letras.

Bueno, J. G. S. (1997). Práticas institucionais e exclusão social da pessoa deficiente. In M. C. Freitas (Org.), Educação especial em debate (pp. 37-54). São Paulo: Casa do Psicólogo.

De Carlo, M. M. R. P. (2001). Se essa casa fosse nossa.... instituições e processos de imaginação na educação especial. São Paulo: Plexus Editora.

Meira, M. E. M. (2007). Psicologia histórico-cultural: fundamentos, pressupostos e articulações com a psicologia da educação. In M. E. M. Meira \& M. G. D. Facci (Orgs.), Psicologia histórico-cultural: contribuições para o encontro entre a subjetividade e a educação (pp. 27-62). São Paulo: Casa do Psicólogo.

Padilha, A. M. L. (2001). Práticas pedagógicas na educação especial: a capacidade de significar o mundo e a inserção cultural do deficiente mental. Campinas, SP: Autores Associados.

Pino, A. (2000). O social e o cultural na obra de Vigotski. Educação e sociedade. Educação e Sociedade, 71, 45-78.

Salvador, N. (1993). Vida de autista: uma saga real e vitoriosa contra o desconhecido. Porto Alegre: AGE.

Sirgado, A. P. (1990). A corrente sócio-histórica de psicologia: fundamentos epistemológicos e perspectivas educacionais. Em Aberto, 48, 61- 67.
Tada, I. N. C. (2005). Dialogando com Amanda: contribuições da teoria histórico-cultural na compreensão de uma jovem com síndrome de Down. Tese de doutorado, Universidade de São Paulo, São Paulo, SP.

Tada, I. N. C. (2009). Os desafios de atuação do psicólogo escolar: da educação especial à educação inclusiva. In A. M. L. Sousa et al. (Orgs.), Psicologia, saúde e educação: desafios na realidade amazônica (pp. 61-83). São Paulo: Pedro e João Editores; Porto Velho: Edufro.

Vigotsky, L. S. (1991). A formação social da mente: o desenvolvimento dos processos psicológicos superiores (4a ed). São Paulo: Martins Fontes.

Vigotsky, L. S. (1995). Obras escogidas III. Problemas del desarrollo de la psique. Madrid: Visor.

Vigotsky, L. S. (1997). Obras completas V. Fundamentos de defectologia. Habana: Editorial Pueblo y Educación.

Vigotsky, L. S. (2000). Psicologia concreta do homem. Educação e Sociedade, 71, 23-44.

Zanella, A. V. (2004). Atividade, significação e constituição do sujeito: considerações à luz da psicologia histórico-cultural. Psicologia em Estudo, 9(1), 127-135. 